\title{
Coalescing Aid Influences on Acrylic Latexes Property and Film Formation Process
}

\author{
Wang Yi, ${ }^{1}$ Chen Zhonghua, ${ }^{1,2}$ and Yu Fei ${ }^{2}$ \\ ${ }^{1}$ School of Materials Science and Engineering, South China University of Technology, Guangzhou 510640, China \\ ${ }^{2}$ Guangzhou Jointas Chemical Co., Ltd., Guangzhou 510640, China
}

Correspondence should be addressed to Wang Yi; wyicslg@163.com

Received 3 August 2016; Accepted 16 October 2016

Academic Editor: Ramki Kalyanaraman

Copyright (c) 2016 Wang Yi et al. This is an open access article distributed under the Creative Commons Attribution License, which permits unrestricted use, distribution, and reproduction in any medium, provided the original work is properly cited.

The coalescing aid of propylene glycol phenyl ether $(\mathrm{PPh})$ influences on the latexes system and its film formation process have been demonstrated in this paper. The latexes with different $T_{g}$ are synthesized by seeded semicontinuous emulsion polymerization. The $\mathrm{PPh}$ have a significant impact on the water evaporation stage, in which $\mathrm{PPh}$ decreased the water evaporation rate for a low $T_{g}$ latex system but accelerated the rate for a high $T_{g}$ latex. This result was quantified using Routh-Russel model which was a useful model for the prediction of the latex particle deformation mechanisms. The different amounts of PPh can change the latex particle deformation mechanisms. The TGA results show that the PPh still exist in the latexes films during drying. The microstructures of the latex film which dry under $70^{\circ} \mathrm{C}$ with the $\mathrm{PPh}$ for different time display that the $\mathrm{PPh}$ can accelerate the polymer molecules motion and the diffusion rate for the latex coalescence stage.

\section{Introduction}

Acrylic latexes are important raw material in a wide range of applications for coatings, house varnishes, and wall paints [1]. Film formation behavior of acrylic latex is a complicated and multistage phenomenon [2]. Recently, opinion on the latex film formation process divided it into three consecutive major stages [3-5]. Stage I is water evaporation; evaporation of water brings the latex polymer particles into close contact. Stage II is particle deformation; the latex particles deform which are induced by surface and osmotic forces associated with passage of water from the interstitial spaces and form a void-free solid structure that is mechanically weak [6]. Stage III is latex coalescence; the polymer molecules diffuse across the intercellular boundaries; the coalescence stage creates entanglements that provide mechanical strength to the film [7-9]. The studies of the process of latex film formation need specific analytical technique to meet the requirement of each stage. The techniques used to study water evaporation stage include MFFT bar [10], gravimetry [11], cryogenic scanning electron microscopy [12], and environmental scanning electron microscopy [13]. Contact atomic force microscopy [14], transmission electron microscopy [15], and scanning electron microscopy [16] are usually used to study latex particle deformation or packing stage. Small angle neutron scattering [17], fluorescence resonance energy transfer [18], and transmission spectrophotometry [19] are often used to study the latex film coalescence or interdiffusion stage.

The Routh-Russel model shows the deformation mechanisms of latex particle are different possible mechanisms depending on two dimensionless parameters, $P e$ and $\bar{\lambda}$. The parameter $\bar{\lambda}$ is defined as the ratio between the time need for film compaction (i.e., for complete particle deformation, $t_{\text {def }}$ ) and the characteristic time for the evaporation of water, $t_{\text {evap }}$, and $\bar{\lambda}$ is written as

$$
\bar{\lambda}=\frac{t_{\text {def }}}{t_{\text {evap }}}=\frac{\eta_{0} R_{0} E}{\gamma_{\mathrm{wa}} H}
$$

where $\eta_{0}$ is the low shear viscosity of the polymer, $\gamma_{\mathrm{wa}}$ is waterair surface tension, $E$ is the evaporation rate, $H$ is the initial film thickness, and $R_{0}$ is the particle size. The parameter $P e$ is defined as the ratio between the characteristic time for the diffusion of the polymer particles from the top to the bottom 
of the film, $t_{\text {diff }}$, and the evaporation time, $t_{\text {evap }}$, and $P e$ is written as

$$
P e=\frac{6 \pi \mu R_{0} H E}{k T},
$$

where $k$ is the Boltzmann constant, $T$ is the temperature (K) of the film formation process, and $\mu$ is the viscosity of a spherical particle in a fluid. Routh-Russel model classifies the particle deformation mechanisms into wet sintering, capillary deformation, dry sintering, and Sheetz deformation [2022]. For wet sintering mechanism, particles are consolidated at close packing in the wet state and quickly deform forced by the polymer-water surface tension. For capillary deformation mechanism, the particle deformation is concurrent with the water evaporation forced by the capillary pressure. For dry sintering mechanism, particles are assumed not to undergo significant deformation until the water evaporates and the particle deformation force is the polymer-air surface tension to deform. For Sheetz deformation mechanism, particles are quickly packing in the film vertical surface by wet sintering to form a skin, the fluid below the compacting particles is at atmospheric pressure, and the upper packed layer is too thin to generate a large capillary pressure. An engineer maybe used this model to investigate how change in a parameter, such as the evaporation rate, film thickness, or particle size, will influence the particle deformation mechanism [23].

The latex used in household varnishes or wall paint usually needs to dry in room temperature, but, with the requirement for hard, scratch-resistant surface, this film cannot be created solely from latex polymer having $T_{g}$ above room temperature, and sometime this paradox can resolute by adding coalescing aid [24], such as PPh and propylene glycol phenyl ether $[25,26]$. The coalescing aids can reduce $T_{g}$ of latex polymer; what is more, the coalescing aid can also increase the polymer diffusivity as the temperature increases above $T_{g}$, and it is enhanced diffusivity which enables continuous and strong films to be created. However, the coalescing aids are usually an organic solvent, which can pollute the air, so the presence status in the latex film is very important [27].

In this article we use dynamic light scattering to study the influence of coalescing aid on the latexes property such as particle size and zeta potential; gravimetry to get the latexes water evaporation rate for latexes film formation stage I and we use the Routh-Russel deformation mechanism model to study the coalescing aid PPh influence on the latex deformation mechanism; scanning electron microscope to investigate the microstructure of latexes films diffusion stage; differential scanning calorimetry to consider the glass temperature of the latex polymer and latex films and particle enthalpy of coalescence; and thermal gravimetric analysis to research the presence of coalescing aid PPh on the latexes films.

\section{Experimental Section}

2.1. Materials. Methyl methacrylate (MMA), Styrene (St), acrylic acid (AA), and butyl acrylate (BA) monomers were used as received from Tianjin Fuyu Agent Company without further purification. Sodium dodecyl sulfate (SDS, Aldrich) was used as emulsifier, potassium persulfate (KPS, Aldrich) was used as initiator, and sodium bicarbonate and ammonia were used as buffer agent. 2,2,4-Trimethyl-1,3-pentanediol monoisobutyrate (PPh, Aldrich) was used as coalescing aid. Doubly deionized (DDI) water was used thought the work.

2.2. Synthesis of BA/St/MMA Latexes by Semiemulsion Polymerization. BA/St/MMA latexes with different glass temperature $\left(T_{g}\right)$ are synthesized by seeded semicontinuous process. First, the emulsifier and monomers dissolve by water in a $500 \mathrm{~mL}$ flask and all of them preemulsify for $1 \mathrm{~h}$. Second, $20 \%$ of the monomer preemulsion is added to a $500 \mathrm{~mL}$ fournecked flask equipped with a reflux condenser, a nitrogen inlet, a sample device, a stainless steel modified anchor stirrer rotating at $250 \mathrm{rpm}$, and a cascade temperature control system. The seed preemulsion heat was $70^{\circ} \mathrm{C}$ with addition of $50 \%$ of the initiator, and when the insulation material is blue and the peak exothermal occurred, the temperature raised to $80^{\circ} \mathrm{C}$. After the temperature stabilized at $80^{\circ} \mathrm{C}$, the remaining monomer preemulsion and initiator dropped, respectively, in $2 \mathrm{~h}$, and then the temperature increased to $90^{\circ} \mathrm{C}$ with incubation for $30 \mathrm{~min}$. When the reaction systems cool to room temperature, aqueous ammonia is added to adjust the $\mathrm{pH}$ to 8-9.

2.3. Particle Sizes. Particle sizes are determined by dynamic light scattering using a Malvern Nanosizer. The latexes are diluted for 800 times.

2.4. Latex Water Evaporation Rate. A Mettler AE260 Delta Range analytical balance is used to record daily mass changes within $0.0001 \mathrm{~g}$, the instrument sensitivity limit. The initial mass as well as any mass change of the glass slide was removed from each calculation so that only changes in the film are displayed.

2.5. Minimum Film Formation Temperature (MFFT). The measurements of the MFFT of the latexes are carried out on MFFT bar. The temperature at the point of the bar that the film becomes optically clear and attains mechanical integrity are defined as MFFT.

2.6. Differential Scanning Calorimeter (DSC). $T_{g}$ of the polymer and latexes films is determined by differential scanning calorimetry, DSC (201 FC, Netzsch Instruments). The samples are placed in an aluminum crucible, cooled to $-30^{\circ} \mathrm{C}$, and then heated to $120^{\circ} \mathrm{C}$ at $10^{\circ} \mathrm{C} / \mathrm{min}$.

A DSC method [28] is used to calculate the enthalpy of coalescence during drying of the latex film. The samples were cast into slides and dried under $-10.0^{\circ} \mathrm{C}$. Two samples with identical weight are placed in sample pans of identical weight $(0.1 \mathrm{mg})$. First, a temperature scan from $-30^{\circ} \mathrm{C}$ to $120^{\circ} \mathrm{C}$ at $10^{\circ} \mathrm{C} / \mathrm{min}$ is performed on a dried latex sample measured against an empty reference pan. Second, the calorimeter was cooled to room temperature and the original sample transferred to the reference holder. A fresh sample was placed in the first sample holder and the heating scan repeated. Third, after cooling, a second run was performed to generate a base line. 
TABLE 1: Properties of the latexes prepared with different proportions of monomer without PPh.

\begin{tabular}{lcccccc}
\hline Name & BA/MMA/St $(w t \%)$ & Solid content $($ wt.\%) & Z-Ave $(\mathrm{nm})$ & PDI & MFFT $\left({ }^{\circ} \mathrm{C}\right)$ & $T_{g}\left({ }^{\circ} \mathrm{C}\right)$ \\
\hline 1027 & $20 / 40 / 40$ & 40 & 139.9 & 0.052 & 75.0 & 67.4 \\
0912 & $40 / 30 / 30$ & 40 & 196.3 & 0.061 & 31.2 & 31.4 \\
\hline
\end{tabular}

2.7. Thermal Gravimetric Analyzer (TGA). TGA measurements were obtained from a thermal gravimetric analysis (NETZSCH STA 449C, Germany) under nitrogen atmosphere at a heating rate of $20^{\circ} \mathrm{C} / \mathrm{min}$ from $30^{\circ} \mathrm{C}$ to $600^{\circ} \mathrm{C}$. The latexes films with coalescing aid formed under room temperature are tested after 7 days for film formation process.

2.8. Scanning Electron Microscope (SEM). The SEM pictures were obtained by field emission scanning electron microscope (Merlin, Carl Zeiss, Germany), and it is used to investigate the microstructure of the latexes films surface. All samples were coated with gold before SEM observation and the magnification is $50 \mathrm{~K}$.

\section{Results and Discussion}

3.1. Properties of the Latexes Prepared with Different Proportions of Monomers without PPh. Two different latexes of BA/ MMA/St (20/40/40 wt.\% for latex 1027 and 40/30/30 wt.\% for latex 0912) at $40 \%$ SC are synthesized by seeded semibatch emulsion process. The properties of the latexes are compared in Table 1. Regarding the film properties, it can be observed that, as expected, $T_{g}$ and the MFFT values rise as the MMA and St weight ratio increased in the formula. The latex 1027 has $T_{g}$ higher than room temperature and the latex has $T_{g}$ approximate to room temperature.

3.2. The Influence of PPh on the Water Evaporation Process of Latexes. The latexes water evaporation rates are calculated under $25^{\circ} \mathrm{C}$ and $50 \%$ humidity. Figure 1 shows the $\mathrm{PPh}$ have a great influence on the latexes films water evaporation rate which is the slope of the curves. The latex evaporation rate is a two-stage drying curve, with a constant rate of mass loss followed by a decreasing rate period. For latex 1027 with a high $T_{g}$, the water evaporation rate is accelerated by the addition of $\mathrm{PPh}$, and the 1027 latexes films cannot form continued films under this condition as shown in Figure 2. According to Routh-Russel model [24, 29, 30], the parameters for latexes particle deformation mechanism are showed in Table 2, and the latexes particle deformation mechanisms are displayed in Table 2. Table 2 indicates that the addition of the PPh has changed the latex's film formation mechanism. However, for latex 0912 with low $T_{g}$, the water evaporation rate is decelerated by the addition of the PPh, and the latexes' films are continuous films as shown in Figure 4. The latex particle deformation mechanism is wet sintering for $0.00 \%-3.75 \%$ amount of the $\mathrm{PPh}$ as $\bar{\lambda}<1$; there is a mixture of capillary deformation, as a water front recedes through the film for $5.00 \%$ amount [24]. If the latex film with a layer of nondeformed particle accumulates at the top surface, then an addition of the PPh will make the particle with a low $T_{g}$ and easily deformed, the driving force for drying sintering is polymerair surface tension which is consistent under the same condition, and the rate of water evaporation will increase. If the top surface particles fuse together to form a continuous film, the rate of water loss will be considerably reduced.

3.3. The Influence of $P P h$ on the Enthalpy of Coalescence for Latexes Films. The latexes films for testing enthalpy of coalescence are drying under $-10^{\circ} \mathrm{C}$ to reduce the diffusion for latex film. The DSC method shows the irreversible thermal changes during the latex film formation process; this method is used to calculate the enthalpy of coalescence indicating the total energy required for the disappearance of the interface of the latex particle and the latex molecules motion making a continuous film for latex. Figure 3 illustrated the latexes films enthalpy of coalescence was decreased with the addition of PPh for latex 1027 and latex 0912, and the PPh could speed up the polymer molecular motion and made the latexes films more uniform during the film formation process. The DSC method determines the latex film or coating film is fully uniform or not. And this method determines how many coalescing aids should be added to the latex formula to get a uniform film under given conditions.

3.4. The Thermal Stability of the Latexes Film with PPh. The effects of $\mathrm{PPh}$ on the thermal stability of the latex films are shown in Figure 4. The first weight loss platform of the TGA curves is the heat decomposition of the $\mathrm{PPh}$; the $\mathrm{PPh}$ is almost decomposed at $330^{\circ} \mathrm{C}$. The latex film with varying amounts of the $\mathrm{PPh}$ decreased as the addition amount of $\mathrm{PPh}$ increased and the formed latex film contained a greater number of $\mathrm{PPh}$. Figure 4 also shows the $\mathrm{PPh}$ cannot change the temperature of maximum weight loss rate and final temperature of decomposition for the latex polymer.

The addition of the PPh can effectively act as a coalescing aid for the latexes film polymer; when we add less than $5.00 \mathrm{wt} . \%$ amount of $\mathrm{PPh}$ to the acrylic latexes, it has little influence on the latex system but can effectively lower its films $T_{g}$ and MFFT, and it can also change the latex water evaporation rate and transform the latex deformation mechanism. The PPh still exist in the latexes films with little amount evaporating to the atmosphere by the result of TGA research.

3.5. The Influence of PPh on the 1027 Latexes Films Microstructure Dry at $70^{\circ} \mathrm{C}$. Figure 5 depicts the microstructure of the 1027 latexes films with $\mathrm{PPh}$ which dry at $70^{\circ} \mathrm{C}$ for different time. The latex particles remained physically distinct and deformation occurred for latex 1027 film with 1.25\% of PPh for $5 \mathrm{~h}$ and they form a continuous film for $7 \mathrm{~h}$, the polymer molecules are diffusing, and the latex particles are losing the original particle morphology within film formation process. 

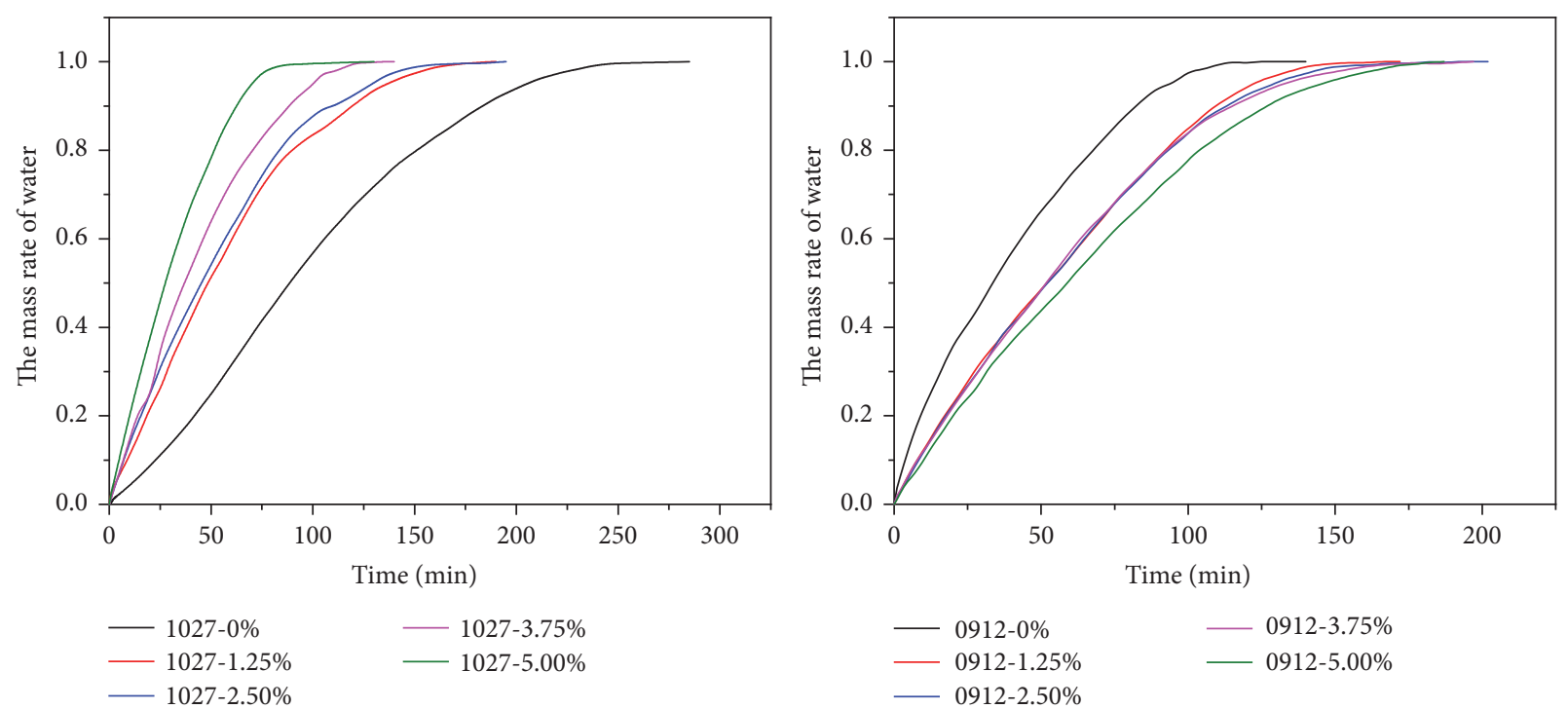

FIGURE 1: Effect of PPh on the latex water evaporation.

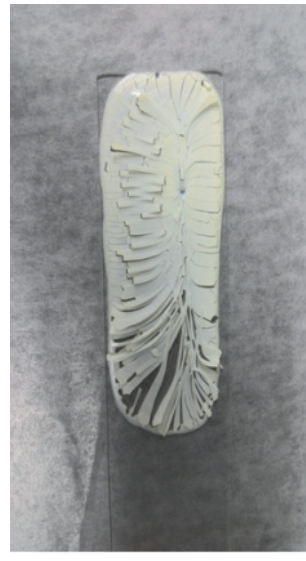

(1027-0\%)

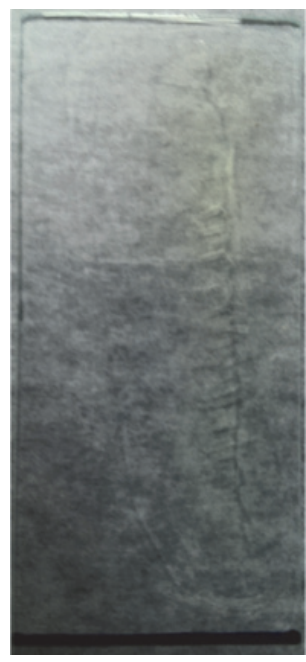

(0912-0\%)

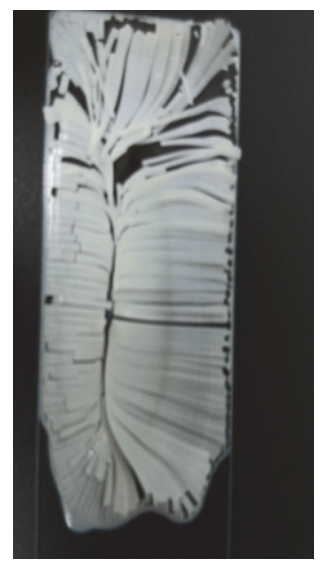

$(1027-1.25 \%)$

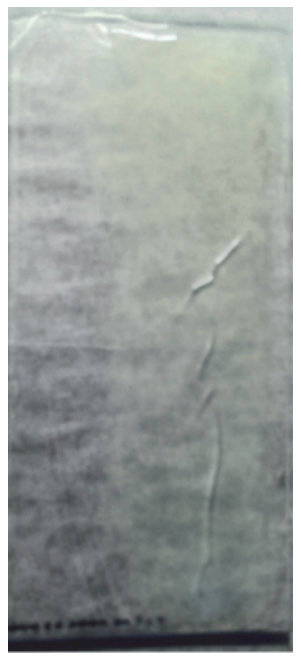

$(0912-1.25 \%)$

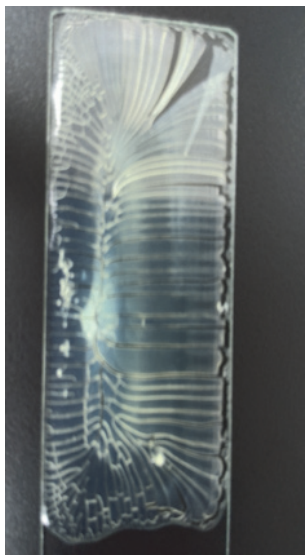

$(1027-2.50 \%)$

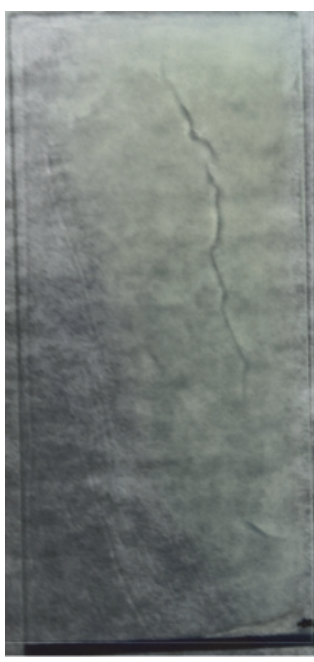

$(0912-2.50 \%)$

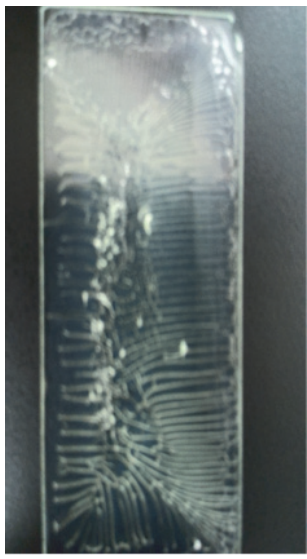

$(1027-3.75 \%)$

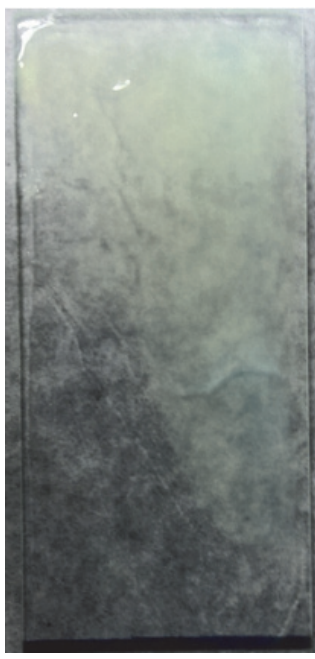

$(0912-3.75 \%)$

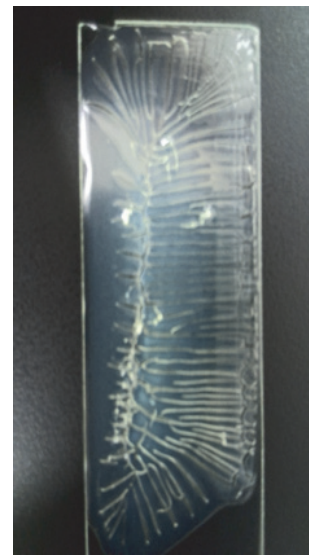

$(1027-5.00 \%)$

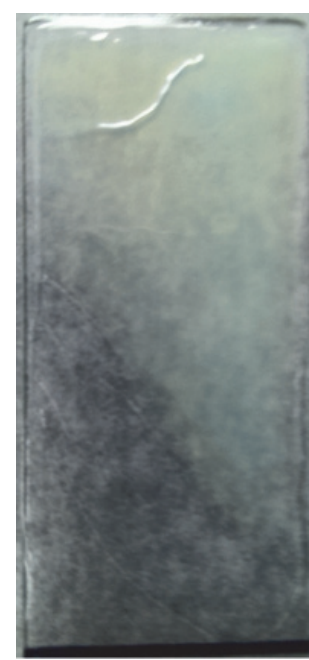

$(0912-5.00 \%)$

Figure 2: Photographs of the latexes films drying at room temperature. 
TABLE 2: The parameters for latex particle deformation mechanism in Routh-Russel model.

\begin{tabular}{lcccccc}
\hline \multirow{2}{*}{ Amount $\%$} & $\bar{\lambda}$ & Latex 1027 & Mechanism & $\bar{\lambda}$ & Le & Mechanism \\
\hline 0.00 & $4.42 \times 10^{13}$ & 0.065 & Dry sintering & $1.73 \times 10^{-4}$ & 0.664 & Wet sintering \\
1.25 & $6.15 \times 10^{5}$ & 0.083 & Dry sintering & $4.97 \times 10^{-4}$ & 0.473 & Wet sintering \\
2.50 & $7.98 \times 10^{3}$ & 0.101 & Mix capillary deformation & $2.63 \times 10^{-3}$ & 0.463 & Wet sintering \\
3.75 & $3.25 \times 10^{1}$ & 0.117 & Capillary deformation & $1.50 \times 10^{-2}$ & 0.463 & Wet sintering \\
5.00 & $1.55 \times 10^{-2}$ & 0.118 & Wet sintering & $1.11 \times 10^{2}$ & 0.378 & Mix capillary deformation \\
\hline
\end{tabular}

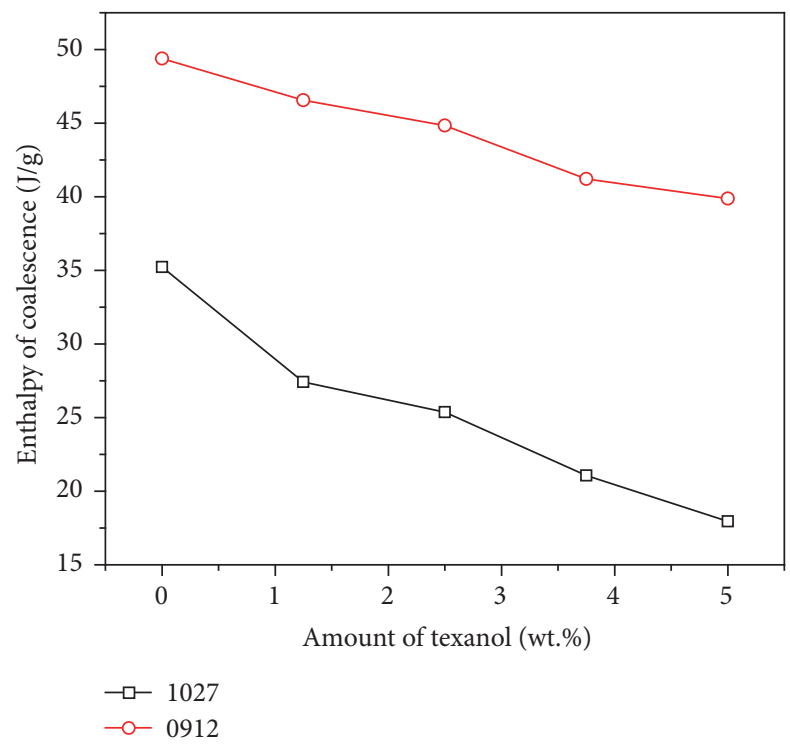

Figure 3: The enthalpy of coalescence for latexes films with $\mathrm{PPh}$.

For latex 1027 with $2.50 \% \mathrm{PPh}$, the film dries at $70^{\circ} \mathrm{C}$ for $5 \mathrm{~h}$, the film becomes a continuous film with a small amount of particles which have interval, and the film becomes a continuous film for $7 \mathrm{~h}$. For latex 1027 with $3.75 \% \mathrm{PPh}$, the film dries at $70^{\circ} \mathrm{C}$ for $2 \mathrm{~h}$, the film becomes a continuous film with a small amount of particles which have interval, and the film becomes a continuous film for $5 \mathrm{~h}$. For latex 1027 with $5.00 \%$ $\mathrm{PPh}$, the film becomes a continuous film for drying $1 \mathrm{~h}$. We can get a result that the coalescing aid $\mathrm{PPh}$ could accelerate the latexes polymer molecule motion. The PPh can accelerate the polymer diffusion rate by reducing $T_{g}$ of latex film, the microstructure result display the polymer molecular motion are speed up by the addition of the PPh.

3.6. The Model of Coalescing Aid Influence on Latex Film Formation. Coalescing aid is very important when designing novel or improved industrial latex coatings. To fully understand the influence of coalescing aid on the formation process of latex film, two practical models should contemplate: the modified Fox equation is utilized to calculate the $T_{g}$ of latex film, and the Routh-Russel model anticipate the particle deformation mechanism.

Through the above experimental part shows the coalescing aid $\mathrm{PPh}$ in the latex have an important role in the process of film formation process, the properties of latex have not changed with the $\mathrm{PPh}$ added to the latex; the mainly role of the PPh occurs after the latex film with water volatilized. With the evaporation of water, latex particles began to gather in surface and form a membrane and the $\mathrm{PPh}$ also began to gather together in this film at the same time; latex 0912 with $5.00 \% \mathrm{PPh}$ is an exact example. Due to the dissolving capability of the $\mathrm{PPh}$ on the film polymer, the polymer particles are fused quickly in film surface; when $T_{g}$ of the latex polymer is close to film forming temperature the surface of the membrane undergoes fusion quickly with the addition of the $\mathrm{PPh}$, the latex particles will form a surface, and the evaporation rate of water can reduce by the formation of the surface layer. The Routh-Russel model can be used to predict the particle deformation mechanism of latex film under this condition. When $T_{g}$ of the latex polymer is higher than film formation temperature, the $\mathrm{PPh}$ acts as a plasticizer to reduce $T_{g}$ of latex polymer according to modified Fox equation. The $\mathrm{PPh}$ is gathered at the surface of the latex film as discussed before, and the $\mathrm{PPh}$ increase the diffusion rate of polymer and change the particle deformation mechanism corresponding to the Routh-Russel model.

\section{Conclusions}

The latex film formation process and the influence of coalescing aid $\mathrm{PPh}$ on the process are studied by a combination of SEM, gravimetry, DLS, and TGA. The latexes with different $T_{g}$ are synthesized by seeded semicontinuous emulsion polymerization. The PPh have a significant impact on the water evaporation stage; the $\mathrm{PPh}$ reduce the water evaporation rate for a low $T_{g}$ latex contrary to accelerating the water evaporation rate for a high $T_{g}$ latex. The $\mathrm{PPh}$ change the latex particle deformation mechanisms with different amount according to Routh-Russel model. The PPh act as a plasticizer to lower $T_{g}$ of latex film and its film formation enthalpy of coalescence. The microstructures of the latex film which dry under $70^{\circ} \mathrm{C}$ with the $\mathrm{PPh}$ for different time display that the $\mathrm{PPh}$ can accelerate the polymer molecules motion and the diffusion rate for the coalescence stage. The TGA results show that the PPh still exist in the latexes films with little amount evaporating to the atmosphere.

In this paper we have demonstrated the $\mathrm{PPh}$ influence on the latexes system and its film formation process. The $\mathrm{PPh}$ can promote the latex forming a continuous film by lowering $T_{g}$ of polymer with little volatilization to the air during film formation process. The Routh-Russel model is a useful model for the prediction of the latex particle deformation 

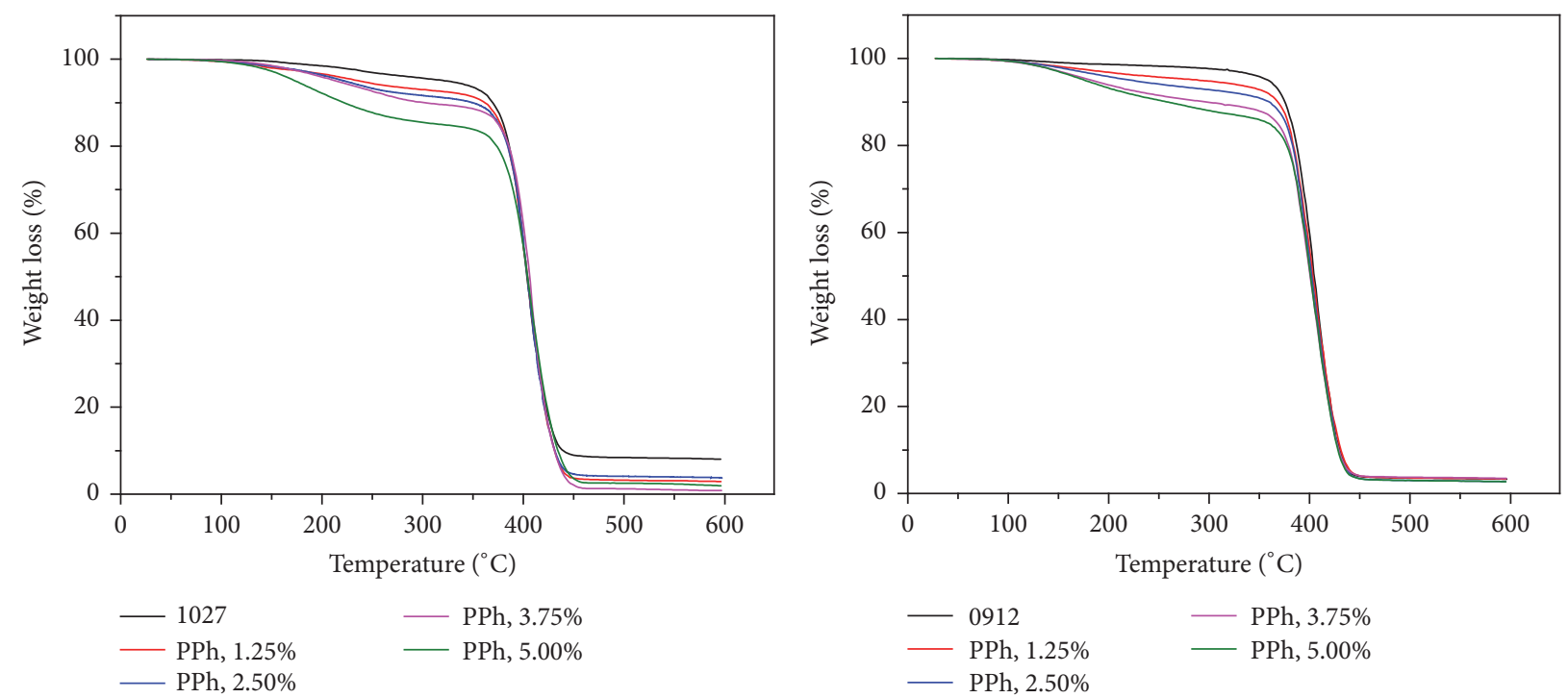

Figure 4: The TGA curves of latexes films with PPh.
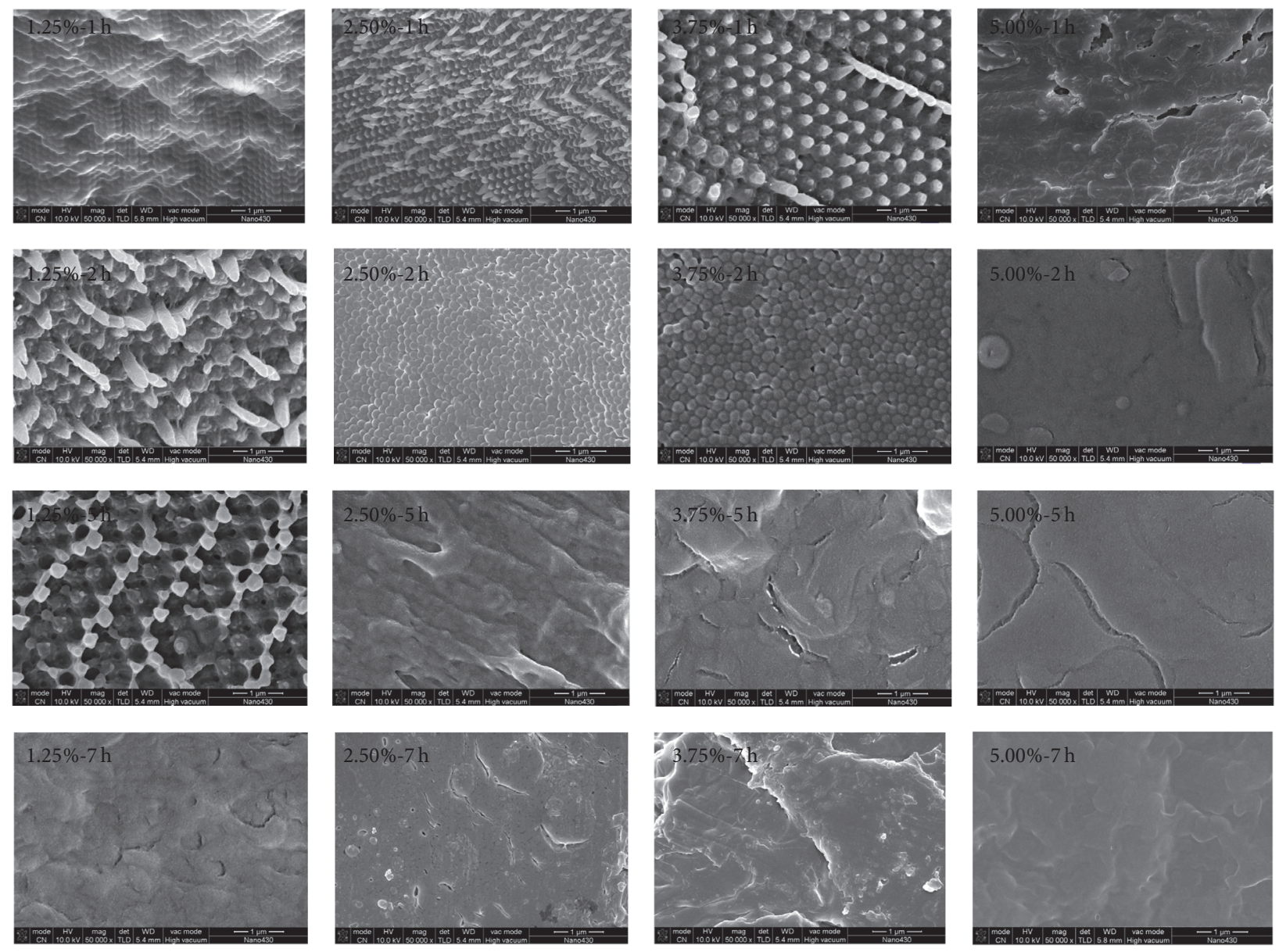

FIgURE 5: The microstructures of 1027 latexes films with PPh dry at $70^{\circ} \mathrm{C}$. 
mechanisms. There is no enough research to prove the occurrence of different mechanisms. The addition of the $\mathrm{PPh}$ cannot change the latexes property, the latex mainly alter the water evaporation rate caused by the addition of the $\mathrm{PPh}$, the deformation mechanisms are changed, and the Routh-Russel model is proved by the addition of the PPh to the latex in our work. Future work will further utilize the quantitative influence of coalescing aid on the latex film formation and its impact on the property of the latex film.

\section{Competing Interests}

The authors declare that they have no competing interests.

\section{Acknowledgments}

This work was financially supported by China Postdoctoral Science Foundation (2013M542176), the National Natural Science Foundation of China (21406073 and 50973033), and Guangzhou Jointas Chemical Ltd. Co.

\section{References}

[1] J. Wu, J. P. Tomba, M. A. Winnik, R. Farwaha, and J. Rademacher, "Effect of gel content on polymer diffusion in poly(vinyl acetate-co-dibutyl maleate) latex films," Macromolecules, vol. 37, no. 11, pp. 4247-4253, 2004.

[2] T. G. Medal, Progress in Colloid \& Polymer Science, vol. 101, Steinkopff, Heidelberg, Germany, 2007.

[3] J. L. Keddie, P. Meredith, R. A. L. Jones, and A. M. Donald, "Kinetics of film formation in acrylic latices studied with multipleangle-of-incidence ellipsometry and environmental SEM," Macromolecules, vol. 28, no. 8, pp. 2673-2682, 1995.

[4] K. I. Dragnevski and A. M. Donald, "An environmental scanning electron microscopy examination of the film formation mechanism of novel acrylic latex," Colloids and Surfaces A: Physicochemical and Engineering Aspects, vol. 317, no. 1-3, pp. 551-556, 2008.

[5] L. A. Felton, "Mechanisms of polymeric film formation," International Journal of Pharmaceutics, vol. 457, no. 2, pp. 423-427, 2013.

[6] F. Simon, S. Kunkel, H. Oehler, D. Lellinger, P. Spahn, and I. Alig, "Investigation of deformation mechanisms during latex film formation by combination of unilateral NMR and near infrared measurements," Progress in Organic Coatings, vol. 70, no. 4, pp. 230-239, 2011.

[7] J. M. Ramos-Fernández, I. Beleña, M. D. Romero-Sánchez, M. Fuensanta, C. Guillem, and Á. M. López-Buendía, "Study of the film formation and mechanical properties of the latexes obtained by miniemulsion co-polymerization of butyl acrylate, methyl acrylate and 3-methacryloxypropyltrimethoxysilane," Progress in Organic Coatings, vol. 75, no. 1-2, pp. 86-91, 2012.

[8] S. Kiil, "Drying of latex films and coatings: reconsidering the fundamental mechanisms," Progress in Organic Coatings, vol. 57, no. 3, pp. 236-250, 2006.

[9] S. W. Zhang, R. Liu, J. Q. Jiang, and H. Y. Bai, "Film formation and mechanical properties of the alkoxysilane-functionalized poly (styrene-co-butyl acrylate) latex prepared by miniemulsion copolymerization," Progress in Organic Coatings, vol. 65, no. 1, pp. 56-61, 2009.
[10] T. F. Protzman and G. L. Brown, "An apparatus for the determination of the minimum film temperature of polymer emulsions," Journal of Applied Polymer Science, vol. 4, no. 10, pp. 8185,1960 .

[11] S. Erkselius, L. Wadsö, and O. J. Karlsson, "Drying rate variations of latex dispersions due to salt induced skin formation," Journal of Colloid and Interface Science, vol. 317, no. 1, pp. 83-95, 2008.

[12] K. K. Price, A. V. McCormick, and L. F. Francis, "CryoSEM investigation of latex coatings dried in walled substrates," Langmuir, vol. 28, no. 28, pp. 10329-10333, 2012.

[13] O. Islam, K. I. Dragnevski, and C. R. Siviour, "On some aspects of latex drying-ESEM observations," Progress in Organic Coatings, vol. 75, no. 4, pp. 444-448, 2012.

[14] R. E. Trueman, E. Lago Domingues, S. N. Emmett, M. W. Murray, J. L. Keddie, and A. F. Routh, "Autostratification in drying colloidal dispersions: experimental investigations," Langmuir, vol. 28, no. 7, pp. 3420-3428, 2012.

[15] J. Park, H. Zheng, W. C. Lee, P. L. Geissler, E. Rabani, and A. P. Alivisatos, "Direct observation of nanoparticle superlattice formation by using liquid cell transmission electron microscopy," ACS Nano, vol. 6, no. 3, pp. 2078-2085, 2012.

[16] Ö. Pekcana, F. Kemeroglua, and E. Ardab, "Measuring backbone activation energy at polymer-polymer interfaces during latex film formation by using a photon transmission method," European Polymer Journal, vol. 34, no. 9, pp. 1371-1378, 1998.

[17] F. Belaroui, B. Cabane, M. Dorget, Y. Grohens, P. Marie, and Y. Holl, "Small-angle neutron scattering study of particle coalescence and SDS desorption during film formation from carboxylated acrylic latices," Journal of Colloid and Interface Science, vol. 262, no. 2, pp. 409-417, 2003.

[18] M. Soleimani, S. Khan, D. Mendenhall, W. Lau, and M. A. Winnik, "Effect of molecular weight distribution on polymer diffusion during film formation of two-component high-/lowmolecular weight latex particles," Polymer, vol. 53, no. 13, pp. 2652-2663, 2012.

[19] M. S. Sunay, O. Pekcan, M. M. Rahman, A. Elaissari, and S. Ugur, "Spectroscopic study of film formation from polystyrene latex/ $\mathrm{TiO}_{2}$ nanocomposites prepared by dip-coating method," Polymer Engineering and Science, vol. 54, no. 2, pp. 288-302, 2014.

[20] A. F. Routh and W. B. Russel, "A process model for latex film formation: limiting regimes for individual driving forces," Langmuir, vol. 15, no. 22, pp. 7762-7773, 1999.

[21] A. F. Routh and W. B. Russel, "A process model for latex film formation: limiting regimes for individual driving forces," Langmuir, vol. 17, no. 25, pp. 7446-7447, 2001.

[22] A. F. Routh, W. B. Russel, J. Tang, and M. S. El-Aasser, "Process model for latex film formation: optical clarity fronts," Journal of Coatings Technology, vol. 73, no. 916, pp. 41-48, 2001.

[23] E. Gonzalez, M. Paulis, M. J. Barandiaran, and J. L. Keddie, "Use of a Routh-Russel deformation map to achieve film formation of a latex with a high glass transition temperature," Langmuir, vol. 29, no. 6, pp. 2044-2053, 2013.

[24] J. L. Keddie and A. F. Routh, Fundamental of Latex Film Formation, Steinkopff, Heidelberg, Germany, 2010.

[25] W. F. Schroeder, Y. Q. Liu, J. P. Tomba, M. Soleimani, W. Lau, and M. A. Winnik, "Effect of a coalescing aid on the earliest stages of polymer diffusion in poly(butyl acrylate-co-methyl methacrylate) latex films," Polymer, vol. 52, no. 18, pp. 3984-3993, 2011.

[26] T. N. Raja, A. M. Brouwer, K. Biemans, T. Nabuurs, and R. Tennebroek, "Detection of coalescing agents in water-borne 
latex emulsions using an environment sensitive fluorescent probe," Photochemical and Photobiological Sciences, vol. 9, no. 7, pp. 975-984, 2010.

[27] Y. C. Wang and M. A. Winnik, "Effect of a coalescing aid on polymer diffusion in latex films," Macromolecules, vol. 23, no. 21, pp. 4731-4732, 1990.

[28] L. A. Cannon and R. A. Pethrick, "Comparison of the effect of reactive and non-reactive steric stabilisers on the mechanism of film formation in methyl methacrylate/butyl acrylate copolymers latexes. Part 1. Differential scanning calorimetry, dynamic mechanical analysis and atomic force microscopy," Polymer, vol. 43, no. 24, pp. 6421-6428, 2002.

[29] R. E. Trueman, E. L. Domingues, S. N. Emmett, M. W. Murray, J. L. Keddie, and A. F. Routh, "Autostratification in drying colloidal dispersions: experimental investigations," Langmuir, vol. 28, no. 7, pp. 3420-3428, 2012.

[30] A. F. Routh, "Drying of thin colloidal films," Reports on Progress in Physics, vol. 76, no. 4, pp. 46603-46632, 2013. 

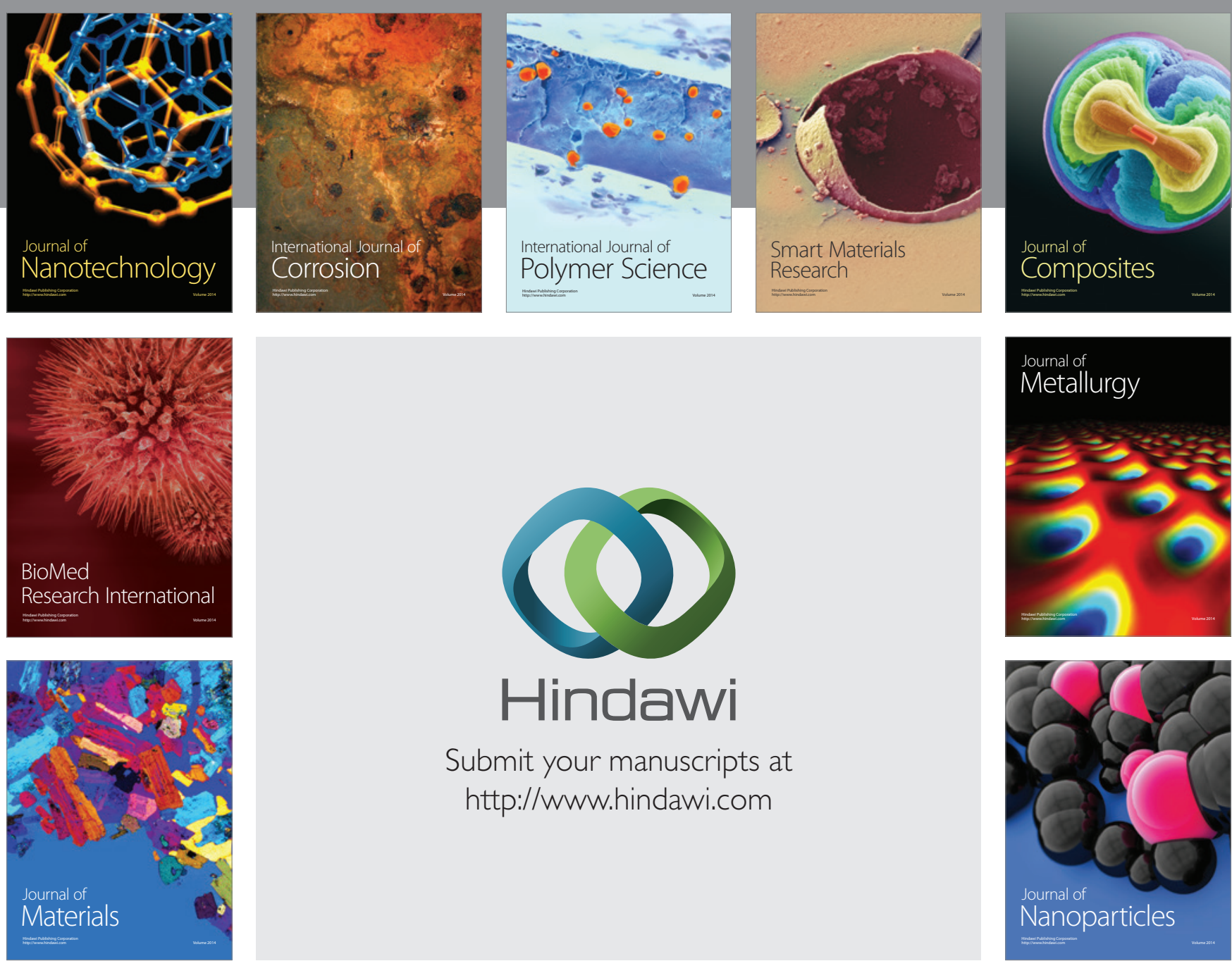

\section{Hindawi}

Submit your manuscripts at

http://www.hindawi.com

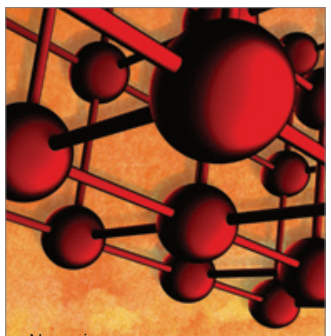

Materials Science and Engineering
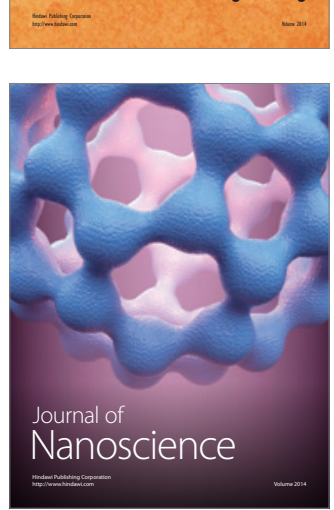
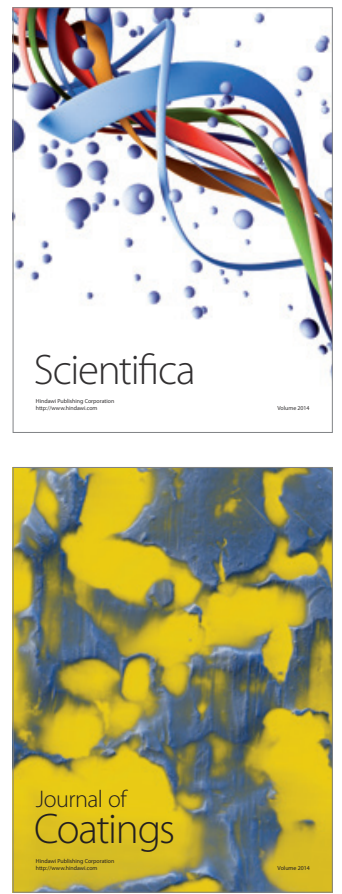
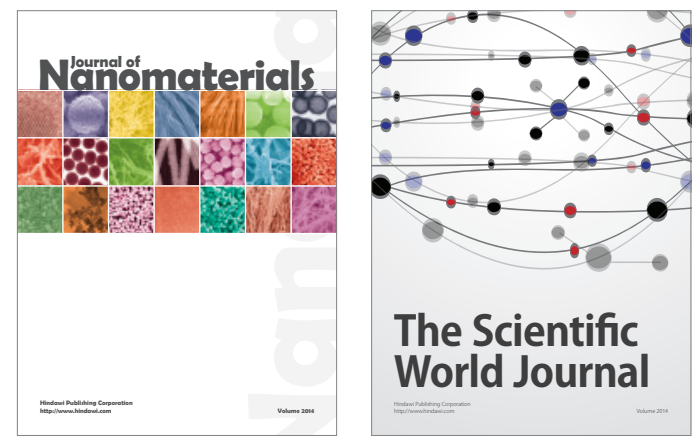

The Scientific World Journal
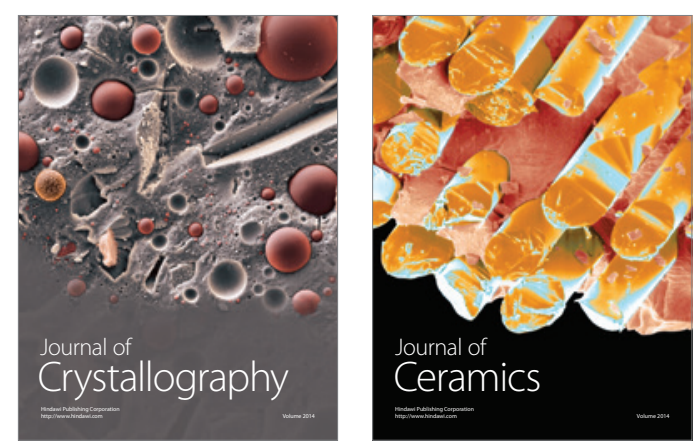
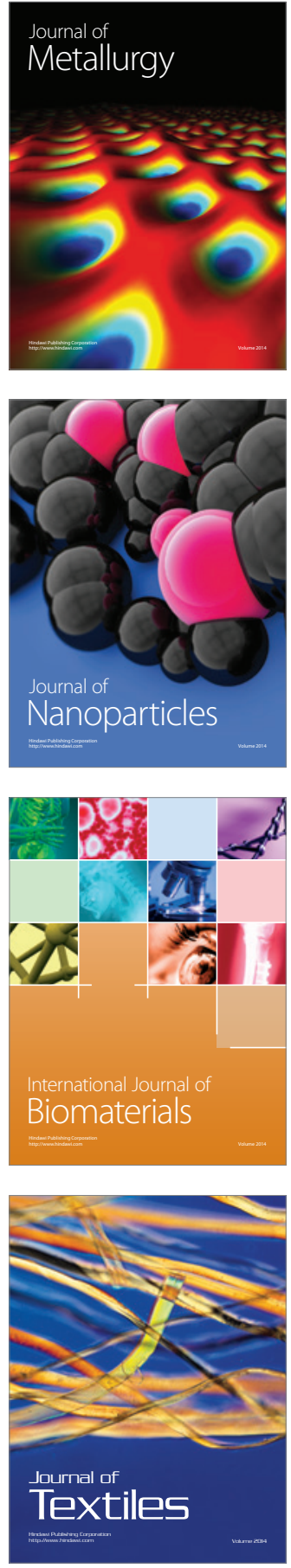